\title{
The Head Kidney of Teleostean Fishes.
}

By

\section{w. L. Calderwood.}

With Plate I.

Until the year 1881, when Balfour wrote on the subject,* the pronephros was generally believed to be a functional kidney, not only in the larval condition, but also in those adult forms described as possessing the organ.

Balfour, in his more detailed paper, published later, $\dagger$ states that in the fishes examined-pike, eel, smelt, and angler-although the pronephros had all the appearance, externally, of a true functional kidney, no uriniferous tubules were present, and that a minute examination only disclosed a degenerate trabecular tissue which he describes as lymphatic.

The angler (Lophius), it may be observed, is generally considered to possess only a head kidney. This organ Balfour found to be in a perfectly functional condition, but he declines to believe that it is a persistent head kidney, and argues from the highly modified structure of the fish that the organ in question is in reality the mesonephros shifted forward from its normal position. He also maintains that in adult Ganoids the head kidney has no longer a renal function. His general conclusion, therefore, is, that since the pronephros was only supposed to persist in Ganoids and Teleosteans, it must be now considered as non-existent except in the embryonic or larval conditions.

Parker $\ddagger$ also supports the conclusions of Balfour by stating that in many instances the mesonephros has grown forward in front of the air-bladder and taken the place of the pronephros.

* The Pronephros of Teleosteans and Ganoids, Brit. Assoc. Reports, 1881, p. 721.

† Quart. Journ. Micros. Science, January, 1882.

$\ddagger$ On the Kidneys of Teleosteans, Brit. Assoc. Report, 1882, p. 577. 
When studying the extraordinary position of the air-bladder in Dactylopterus volitans* I was struck by the very pronounced head kidney, and by its peculiar position. In this fish the pronephros is entirely separated from the body kidney and is situated anterior to the abdominal cavity in the same transverse plane as the heart. In the paper referred to it is shown that the swimming bladder of Dactylopterus is divided, on each side, into two main portions, one large and muscular, the other thin-walled but surrounded by bone and situated above and anterior to the muscular portion. Below this secondary portion, and in front of the primary, there is a cavity of inverted pyramidal shape, formed entirely of bone except on the anterior aspect.

The pronephros fills this cavity, its anterior surface coming in contact with the extremely vascular membrane lining the posterior portion of the branchial chamber.

The body kidney is situated behind the large muscular portion of the swimming bladder, and receives in a concavity the rounded posterior end of the bladder.

Communication between the two is, however, maintained by a canal formed in the ventral surfaces of the anchylosed first four vertebræ of the spinal column. This canal tunnels through what would otherwise be the bases of the transverse processes, and so is protected from any movements of the bladder which surrounds, and lies largely above the spinal column in this region.

The appearance of the pronephros when sectioned is represented in fig. 1. It is apparently a functional kidney. Sections of the body kidney give an exactly similar appearance, only in the majority of sections a greater number of uriniferous tubules are present, and no doubt this organ is capable of secreting more urine than the other. In comparing the organs, I took at random, ten sections from slides of head kidney sections, and ten from slides of body kidney, and used a lens with a wide angle (Zeiss D). I counted 87 sectioned tubules for the head kidney, and 144 for the body kidney; i.e. a majority of 57 for the body kidney.

This difference between the two organs may go to show that in Dactylopterus the degeneration of the pronephros is only commencing, but I think the conditions justify me in believing the organ to have a renal function.

In attempting to follow the course of degeneration I examined Cyclopterus humpus. Here the pronephros, although joined to the mesonephros, is yet easily distinguishable from it. The single body kidney somewhat resembles an elongated cone in form, the apex

* On the Swimming Bladder and Flying Powers of Dactylopterus volitans, Proc. Roy. Soc. Edin., vol. xvii, 1890. 
being posterior. At its broadest or anterior end it suddenly divides, each branch becoming constricted and then again dilating to form the large head kidney. The appearance of sections taken at this constricted part in no way differs from that of the body kidney proper, but in the fully-grown adult, the part where the dilatation to the head kidney begins shows an altered condition; uriniferous tubules have become fewer in number, blood-vessels have disappeared, and the cells of the surrounding matrix seem to have multiplied. Still further forward, hardly any trace of tubules remains. This condition is shown in fig. 2 .

Here, elongated empty spaces alone denote the former position of tubules, and the granular matrix forms almost the entire organ ; whereas in sections of the body kidney, the convoluted tubules lie so thickly together as to leave room for little surrounding substance. As to the nature of this matrix, which Balfour considers to be lymph, I am not prepared to make a positive statement. Looked at with a very high power, the granules are seen to be nucleated, and to possess a more or less irregular outline, but they are extremely small, and it seems to me the entire organ presents a singularly solid mass to be analagous to a lymph gland. Capillaries do not appear to exist, nor can I find any adenoid reticulum.

The very early condition of the pronephros is seen in fig. 3-a thirteen days' embryo. Here the tubules are still few in number, but large in proportion to the size of the organ, and there is a considerable mass of granular tissue. As development proceeds the tubules multiply, and there is consequently less granular substance, but a Cyclopterus three quarters of an inch long shows little difference in the condition of its pronephros, from the figure of the thirteenth day embryo.

I have preserved almost a complete series of specimens from the fertilization of the egg onwards, but find that not till Cyclopterus has become sexually mature does its head kidney commence to degenerate. Fig. 4 shows a section of the pronephros of what may be described as a half grown or small adult fish, but owing to the specimen having been preserved in strong spirit, great shrinkage has taken place. This figure is in strong contrast to the condition in the old fish as seen in fig. 2, yet it is very similar to the figure showing the old state in Dactylopterus, fig. 1.

Returning now to the statement of Balfour that, in some instances, the mesonephros grows forward so as to take up the position formerly occupied by the pronephros, and again considering the case of Dactylopterus, two objections suggest themselves. First, in the developing embryo, the segmental duct and pronephros are developed at a much earlier period than the mesonephros, and must be 
permanently separated from all abdominal viscera before the completion of the mesonephros. Second, from the manner in which the head kidney is encased in bone, it appears that if what I am naming head kidney is in reality a part of the body kidney grown forwards (since it is functional), it must, to have taken up its position in the head, have penetrated both the air-bladder and the scapular arch.

Again, does the similar condition of the pronephros in a small adult Cyclopterus and an old adult Dactylopterus, not indicate that in some fishes (e.g. Dactylopterus) the degeneration of the organ in question has not yet reached that point demonstrable in many? This seems to me to be a more natural view than to suppose that any functional kidney occupying a position in the head is merely the whole or part of the true body kidney translated from its normal position.

If, then, I establish the fact that the head kidney in Dactylopterus is in reality a functional pronephros persisting in the adult, the statement of Balfour that such an organ does not exist must be modified, and a compromise made between it and the older hypothesis of Rosenberg, who first demonstrated that the head kidney was the persistent pronephros.

I think the above evidence, therefore, favours the conclusion that in adult Teleosteans the renal function is performed in some instances by the body kidney only; in others by the head kidney only; and in others - probably a very limited number-by both the body and head kidneys. Besides Dactylopterus, I am aware of only one instance where the head kidney is described as possessing tubules and Malpighian bodies, viz. in Fierasfer. (Carlo Emery, Le Specie del Genere Fierasfer nel Golfo di Napoli, Leipzig, 1880).

\section{EXPLANATION OF PLATE I.}

\section{Illustrating Mr. Calderwood's paper on "The Head Kidney of Teleostean Fishes."}

Frg. 1.-Transverse section of head kidney of an adult Dactylopterus. Zeiss' D, oc. 2. FIG. 2.-Transverse section of head kidney of adult Cyclopterus. Zeiss' D, oc. 2.

FrG. 3.-Longitudinal section of pronephros of Cyclopterus embryo at thirteenth day. Zeiss' D, oc. 2.

FIG. 4.-Transverse section of head kidney of young adult Cyclopterus. From spirit specimen. Zeiss' D, oc. 2. 


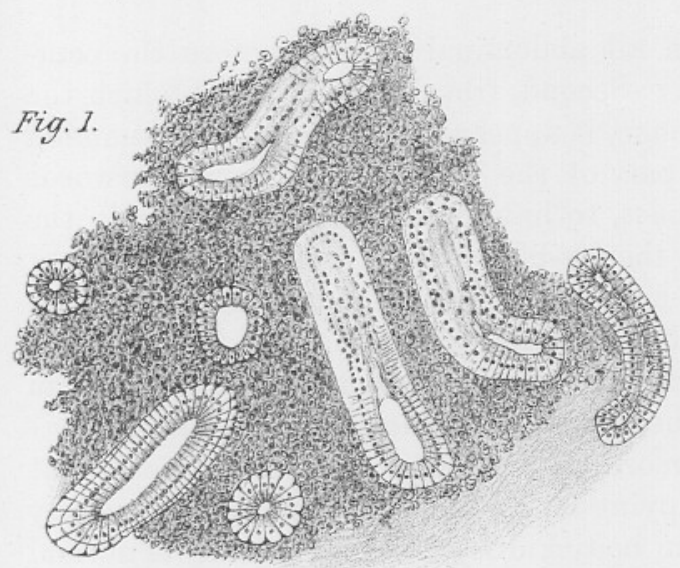

Fig. 2.

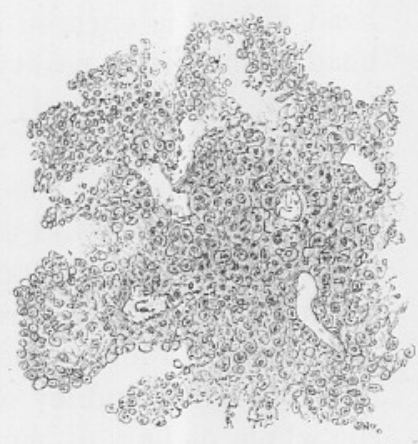

Fig. 3.

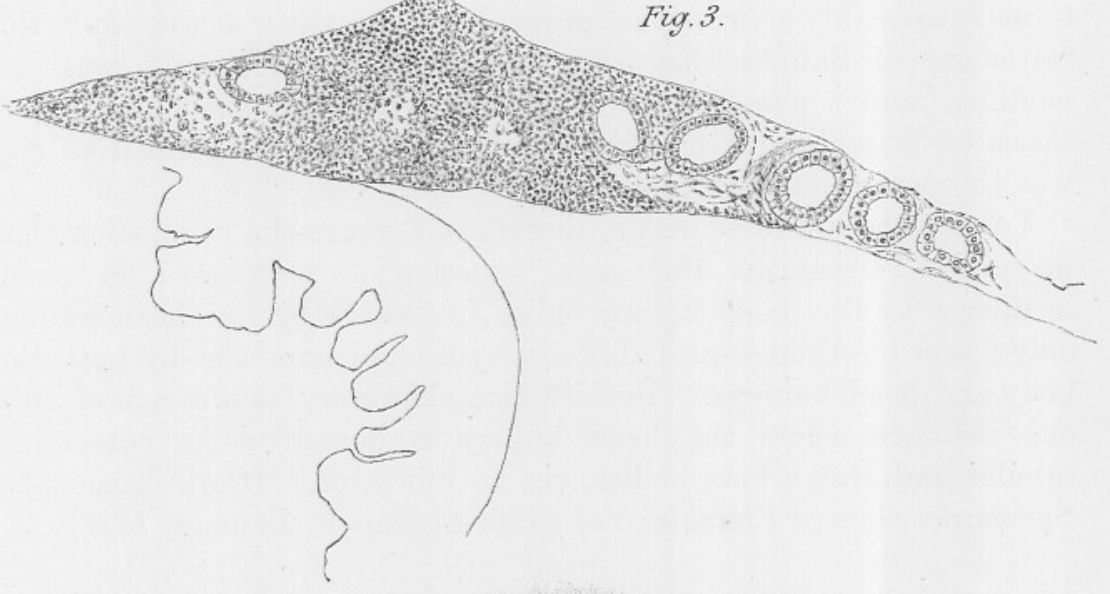

Fig. 4.

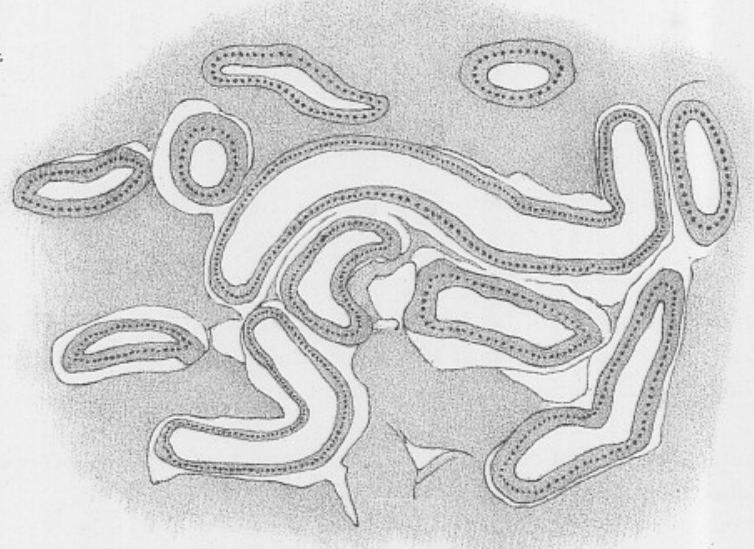

